\title{
PURIFICAÇÃO DE LIPASE PRODUZIDA A PARTIR YARROWIA LIPOLYTICA POR MEIO SISTEMA AQUOSO BIFÁSICO E ULTRAFILTRAÇÃO
}

\author{
T.C. SANTOS ${ }^{1}$, R. C. F. BONOMO ${ }^{2}$, M. FRANCO ${ }^{3}$, P. V. FINOTELLI ${ }^{4}$ e P. F. F. AMARAL ${ }^{5}$ \\ ${ }^{1}$ Universidade Federal do Rio de Janeiro, Departamento de Engenharia Bioquímica \\ ${ }^{2}$ Universidade Estadual do Sudoeste da Bahia, Departamento de Estudos Básicos e Instrumentais \\ ${ }^{3}$ Universidade Estadual de Santa Cruz, Departamento de Ciências Exatas e Tecnológicas. \\ ${ }^{4}$ Universidade Federal do Rio de Janeiro, Departamento de Produtos Naturais e Alimentos
}

\section{E-mail para contato: tcsantos@ufrj.br}

O uso de enzimas em diferentes segmentos industriais é crescente. A obtenção de enzimas compreende o processo fermentativo, as etapas de separação e concentração de produto, seguidos ou não da sua purificação e secagem. Com vistas ao uso do setor biotecnológico, a lipase foi produzida a partir da Yarrowia lipolytica, o extrato bruto obteve a atividade enzimática de $75 \mathrm{U} / \mathrm{mL}$. Com esse extrato foram utilizadas duas formas de purificação parcial, por sistema aquoso bifásico (SAB) com o uso de polietilenoglicol $(1500 \mathrm{Da})$ e fosfato de sódio $(20 \% \mathrm{~m} / \mathrm{m})$ com variação de $\mathrm{pH}$ (6 e 8) em $4^{\circ} \mathrm{C}$ e $25^{\circ} \mathrm{C}$, e o sistema de ultrafiltração tangencial (UF), em membranas de 10 $\mathrm{kD}$. Os resultados demonstram que a purificação realizada pelo $\mathrm{SAB}$, o fator de purificação (FP) quantificado foi de 34,74, já para a ultrafiltração o FP foi 6,55. Todos os tratamentos apresentaram tolerância a uma ampla faixa de temperatura (20 a $\left.50^{\circ} \mathrm{C}\right)$ e $\mathrm{pH}(4$ a 8,5$)$ a 150 min de exposição, como atividade relativa superior a $50 \%$.

\section{INTRODUÇÃO}

As lipases (glicerol éster hidrolases, E.C.3.1.1.3) são enzimas hidrolíticas em seu ambiente natural. Estas possuem a função de catalisar a hidrólise de triacilgliceróis aos correspondentes ácidos graxos e glicerol (ZAREVUCKA et al., 1995). Elas representam um grupo de biocatalisadores acessíveis e de baixo preço, que em geral, são flexíveis quanto à sua especificidade. São as enzimas mais empregadas tanto em nível industrial (indústria alimentícia, de cosméticos e perfumes, biomédica, pesticidas, detergentes, entre outras) como acadêmico (BREUER et al., 2004). As lípases são capazes de catalisar não apenas reações de hidrólise, mas também de síntese em meio aquorestritos, como reação de esterificação, interesterificação, transesterificação, alcoólise e aminólise. Além disso, as lipases usualmente atuam sobre substratos não naturais (JAEGER e EGGERT, 2002).

A maioria dos custos de produção para um produto biológico simples reside na estratégia de purificação. Existe uma grande necessidade de se estabelecer técnicas de biosseparação eficientes, efetivas e econômicas em larga escala, que permitam atingir elevado grau pureza e rendimento de recuperação, mantendo a atividade biológica da molécula. A utilização dos SABs, compatível com os 
processos de biosseparações, permite isolar moléculas com atividade biológica de misturas complexas, e oferece vantagens como curto tempo de processamento, baixo custo e facilidade de aplicação tanto em escala piloto como em escala industrial (COIMBRA e TEIXEIRA, 2009).

A maioria das lipases microbianas são extracelulares e o processo de cultivo é usualmente seguido pela remoção das células do meio de cultivo. $\mathrm{O}$ meio livre de células pode ser concentrado por ultrafiltração, ou com o uso dos Sistemas Aquosos Bifásicos (SABs), compatível com os processos de biosseparações, permite isolar moléculas com atividade biológica de misturas complexas, e oferece vantagens como curto tempo de processamento, baixo custo e facilidade de aplicação tanto em escala piloto como em escala industrial (COIMBRA e TEIXEIRA, 2009).

O objetivo deste trabalho foi a purificação da lipase produzida com a levedura Yarrowia lipolytica através da ultrafiltração tangencial e com o uso do sistema aquoso bifásico.

\section{MATERIAIS E METODOS}

\subsection{Microrganismo}

A levedura empregada no presente trabalho foi uma cepa selvagem de Yarrowia lipolytica 583 (IMUFRJ 50682) selecionada de um estuário da Baía de Guanabara no Rio de Janeiro, Brasil (HAGLER e MENDONÇA-HAGLER, 1981) e identificada pelo Instituto de Microbiologia do Centro de Ciências da Saúde da Universidade Federal do Rio de Janeiro (AMARAL, 2007).

As células foram conservadas a $4^{\circ} \mathrm{C}$ após 24 horas de crescimento em tubos de ensaio com meio YPD ("Yeast Extract, Peptone, Dextrose") contendo (em p/v): extrato de lêvedo 1\%, peptona 2\%, glicose 2\% e Agar-agar 2\% (AMARAL, 2007).

\subsection{Cultivos}

A partir dos tubos contendo as células preservadas em meio sólido YPD (descrito no item 2.1) inoculava-se, de forma estéril com uma alça de platina, $200 \mathrm{~mL}$ de meio de cultivo YPD em erlenmeyers de $500 \mathrm{~mL}$. Após cerca de 70 horas em um incubador rotatório a $29^{\circ} \mathrm{C}, 160 \mathrm{rpm}$, a absorbância. $(570 \mathrm{~nm})$ de uma amostra deste cultivo foi determinada e, em seguida as células foram centrifugadas de forma estéril a $3.000 \mathrm{~g}$ por 10 minutos e ressuspensas em $10 \mathrm{~mL}$ de meio de cultivo servindo de inoculo dos experimentos que foram descritos nos itens posteriores. $\mathrm{O}$ volume centrifugado desse pré-inóculo era suficiente para se obter uma concentração inicial de células de, aproximadamente, $1,0 \pm 0,1 \mathrm{mg}$ p.s. cel/mL nos meios de cultivo \% (AMARAL, 2007).

\subsection{Obtenção do extrato enzimático}

Após o período ótimo de fermentação, o meio foi coletado e centrifugado a temperatura ambiente durante 10 min a $2016 \mathrm{~g}$. O sobrenadante foi utilizado como extrato enzimático, uma vez que a Yarrowia lipolytica produz lípase extracelular (KORDEL et al., 1991). 


\subsection{Determinação da atividade lipolítica}

A atividade lipolítica foi determinada segundo a metodologia descrita por Macedo e colaboradores (1997). Para isso foi utilizado uma emulsão contendo $5 \mathrm{~mL}$ de azeite de oliva e goma arábica a $7 \%, 2 \mathrm{~mL}$ de tampão fosfato de sódio pH $7(10 \mathrm{mM})$ e $1 \mathrm{~mL}$ de extrato enzimático. A mistura foi incubada por 30 minutos e $150 \mathrm{rpm}$ em agitador orbital. A reação foi interrompida pela adição de $15 \mathrm{~mL}$ de solução acetona/etanol (1:1 em volume). Os ácidos graxos liberados durante a reação foram titulados com $\mathrm{NaOH} 0,05 \mathrm{~N}$ usando fenolftaleína como indicador. Um branco contendo o mesmo meio reacional que os ensaios com a enzima inativa foi utilizado. $\mathrm{O}$ cálculo da atividade enzimática foi efetuado segundo a Equação 1.

$$
A\left(\mu \frac{\operatorname{mol}}{g} \cdot \min \right)=\frac{\left(V_{a}-V_{b}\right) \cdot M \cdot D \cdot 10^{6}}{t \cdot v}
$$

Onde:

A é a atividade lipolítica, $V a$ é o volume de $\mathrm{NaOH}$ gasto na titulação da amostra $(\mathrm{mL})$;

$V b$ é o volume do $\mathrm{NaOH}$ gasto na titulação do branco;

$D$ é a diluição da amostra; $M$ é a concentração da solução de $\mathrm{NaOH}$;

$v$ é o volume de extrato bruto $(\mathrm{mL}) \mathrm{e}$

$t$ é o tempo de reação (min).

Uma unidade de atividade de lipase foi definida como a quantidade de enzima que libera $1 \mu \mathrm{mol}$ de ácido graxo por minuto.

\subsection{Determinação do teor de proteínas totais}

A concentração de proteínas no extrato enzimático foi determinada segundo a metodologia descrita por Bradford (1976), tendo como padrão a albumina de soro bovino.

\subsection{Sistema aquoso bifásico (SAB)}

Foi utilizado o sistema proposto por Padillha et al. (2010). Foram preparadas soluções de PEG 1500 a $50 \%$ p/p e soluções tampão fosfato de pHs 6 e 8, durante 12 horas em incubadora BOD. Após esse processo a solução que apresou maior atividade especifica enzimática foi submetida a um sistema com membranas de dialise (850 SIGMA) para recuperação final do produto.

As Equações 2 e 3 serão utilizadas para cálculo dos parâmetros $K_{\text {prot }}, K_{\text {ativ }}$, onde FL é a fase leve (PEG) e FP a fase pesada (sal fosfato).

$$
K_{\text {prot }}=\frac{\text { proteína(FP) }}{\text { proteína(FL) }} \quad \text { (Eq. 2) }
$$




\section{$K_{\text {ativ }}=\frac{\text { atividade }(\mathrm{FP})}{\text { patividad }(\mathrm{FL})}$ (Eq. 3)}

\subsection{Ultrafiltração tangencial}

O extrato bruto clarificado livre de partículas foi submetido a uma ultrafiltração tangencial, utilizando-se uma membrana de polipropileno em com diâmetro de corte de 10 kDa em temperatura ambiente, 150 psi de pressão e com $200 \mathrm{rpm}$.

\subsection{Cálculo do fator de purificação}

Para o cálculo do fator de purificação (FP), utilizou-se da Equação 5.

$$
F P=\frac{A E}{A E(\text { Bruta })} \quad(\text { Eq. } 4)
$$

E para a atividade específica usou-se da Equação 6.

$$
A E=\frac{\text { Atividade de lipase }}{\text { concentraçăo de proteina }}
$$

Sendo:

$A E$ : atividade específica das fases leve e pesada.

$A E$ (Bruta): atividade específica da enzima bruta.

\section{RESULTADOS E DISCUSSÃO}

Com o processo fermentativo a atividade da lipase (extrato bruto livre de células) atingiu 58,3 U/mL e a proteína solúvel $0,315 \mathrm{mg} / \mathrm{mL}$, conforme demostrados na Tabela 1 .

\begin{tabular}{|c|c|c|c|c|c|}
\hline \multicolumn{6}{|c|}{ Sistema a $4^{\circ} \mathrm{C}$} \\
\hline Fase & $\mathrm{pH}$ & $\begin{array}{c}\text { Atividade } \\
\text { Enzimática }(\mathrm{U} / \mathrm{mL})\end{array}$ & $\begin{array}{c}\text { Protéina } \\
\text { soluvel }(\mathrm{mg} / \mathrm{mL})\end{array}$ & $\begin{array}{c}\text { Atividade } \\
\text { Especifica }(\mathrm{U} / \mathrm{mg})\end{array}$ & $\begin{array}{c}\text { Fator de } \\
\text { Purificação }\end{array}$ \\
\hline Superior $^{1}$ & 6 & $2,99( \pm 0,03)$ & $0,183( \pm 0,09)$ & $16,33( \pm 0,02)$ & $0,08( \pm 0,05)$ \\
\hline Inferior $^{2}$ & 6 & $53,83( \pm 0,05)$ & $0,0084( \pm 0,01)$ & $6408,33( \pm 0,05)$ & $34,74( \pm 0,03)$ \\
\hline Superior ${ }^{1}$ & 8 & $40,91( \pm 0,01)$ & $0,114( \pm 0,02)$ & $358,85( \pm 0,02)$ & $1,94( \pm 0,02)$ \\
\hline Inferior $^{2}$ & 8 & $10,02( \pm 0,02)$ & $0,11( \pm 0,02)$ & 92,77 & $0,50( \pm 0,02)$ \\
\hline \multicolumn{6}{|c|}{ Sistema a $25^{\circ} \mathrm{C}$} \\
\hline Fase & $\mathrm{pH}$ & $\begin{array}{c}\text { Atividade } \\
\text { Enzimática }(\mathrm{U} / \mathrm{mL})\end{array}$ & $\begin{array}{c}\text { Protéina } \\
\text { soluvel }(\mathrm{mg} / \mathrm{mL})\end{array}$ & $\begin{array}{c}\text { Atividade } \\
\text { Especifica }(\mathrm{U} / \mathrm{mg})\end{array}$ & $\begin{array}{c}\text { Fator de } \\
\text { Purificação }\end{array}$ \\
\hline
\end{tabular}

Tabela 1 - Sistema Aquoso Bifásico com PEG 1500 


\begin{tabular}{|l|c|c|c|c|c|}
\hline Superior $^{1}$ & 6 & $1,36( \pm 0,05)$ & $0,15( \pm 0,03)$ & $8,94( \pm 0,02)$ & $0,05( \pm 0,03)$ \\
\hline Inferior $^{2}$ & 6 & $12,83( \pm 0,1)$ & $0,051( \pm 0,06)$ & $251,56( \pm 0,02)$ & $1,36( \pm 0,05)$ \\
\hline Superior & 8 & $10,02( \pm 0,02)$ & $0,11( \pm 0,04)$ & $92,77( \pm 0,02)$ & $0,50( \pm 0,03)$ \\
\hline Inferior & 8 & $1,05( \pm 0,01)$ & $0,25( \pm 0,01)$ & $4,21( \pm 0,02)$ & $0,023( \pm 0,04)$ \\
\hline
\end{tabular}

2 Fase constituida de aproximadamente $95 \%$ de tampão estoque fosfato de potássio

Os resultados demostrados na Tabela 1 , as maiores atividades da lipase foram obtidas a $4^{\circ} \mathrm{C}$, apresentado um maior índice de purificação com o sistema tamponado ao pH 6 na fase inferior, constituída basicamente por solução tampão fosfato, o que garante maior facilidade de recuperação da biomolécula após submissão no sistema aquoso.

Com a ultrafiltração a atividade final da enzima lipase do extrato concentrado foi de 128,15 $\mathrm{U} / \mathrm{mL}$, com $0,106 \mathrm{mg} / \mathrm{ml}$ de proteína solúvel, com atividade especifica 1208,96. Assim o fator de purificação (F.P.) foi estimado em 6, 55. No sistema de ultrafiltração o volume inicial foi 1 litro com recuperação final de $200 \mathrm{~mL}$.

Outras técnicas empregadas na purificação de lipases são citadas por Saxena e colaboradores (2003), como, por exemplo: dois processos usados para obtê-las de C. viscosum por meio do uso de micelas reversas de AOT/iso-octano tendo uma recuperação da atividade em $91 \%$ e fator de purificação de 4,3; e outro com o emprego de cromatografia usando Amberlite CG e Shefadex com recuperação da atividade de 2,8\% e fator de purificação de 23; ou ainda de B. Streamthermofilus por cromatografia com CM-Sefarose e DEAE-Sefarose, obtendo uma recuperação da atividade enzimática de 62,2\% e fator de purificação de 11,6. Padilha e colaboradores (2009) purificaram a lipase de Pseudomonas cepacia usando cromatografica de troca iônica por adsorção em leito expandido. Para o grau de expansão 1,5 vezes a altura do leito fixo, os autores recuperaram a atividade enzimática em 102,45\%, com fator de purificação próximo a 80.

Os ensaios de estabilidade a temperatura e pH são apresentados nas Figuras 1 e 2, em a lipase do processo de ultrafiltração foi mais estável que a lipase purificada com o SAB, mas mesmo com ambos tratamentos, a lipase apresentou tolerância a uma ampla faixa de temperatura $\left(20\right.$ a $\left.50^{\circ} \mathrm{C}\right)$ e $\mathrm{pH}$ $(4$ a 8,5) a 150 min de exposição, como atividade relativa superior a $50 \%$. 

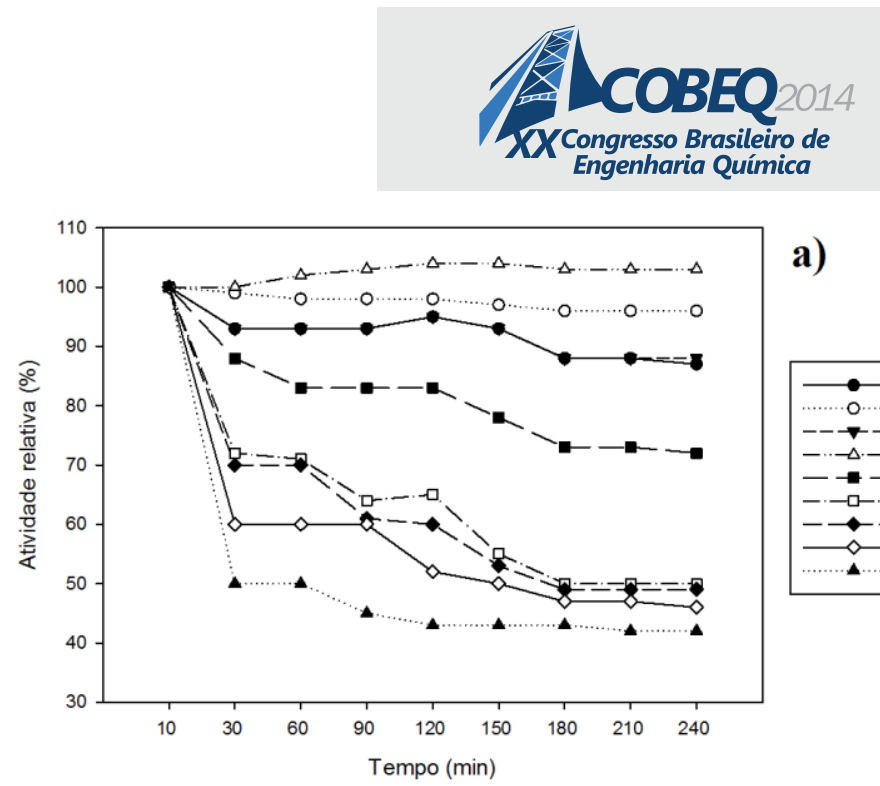

a)
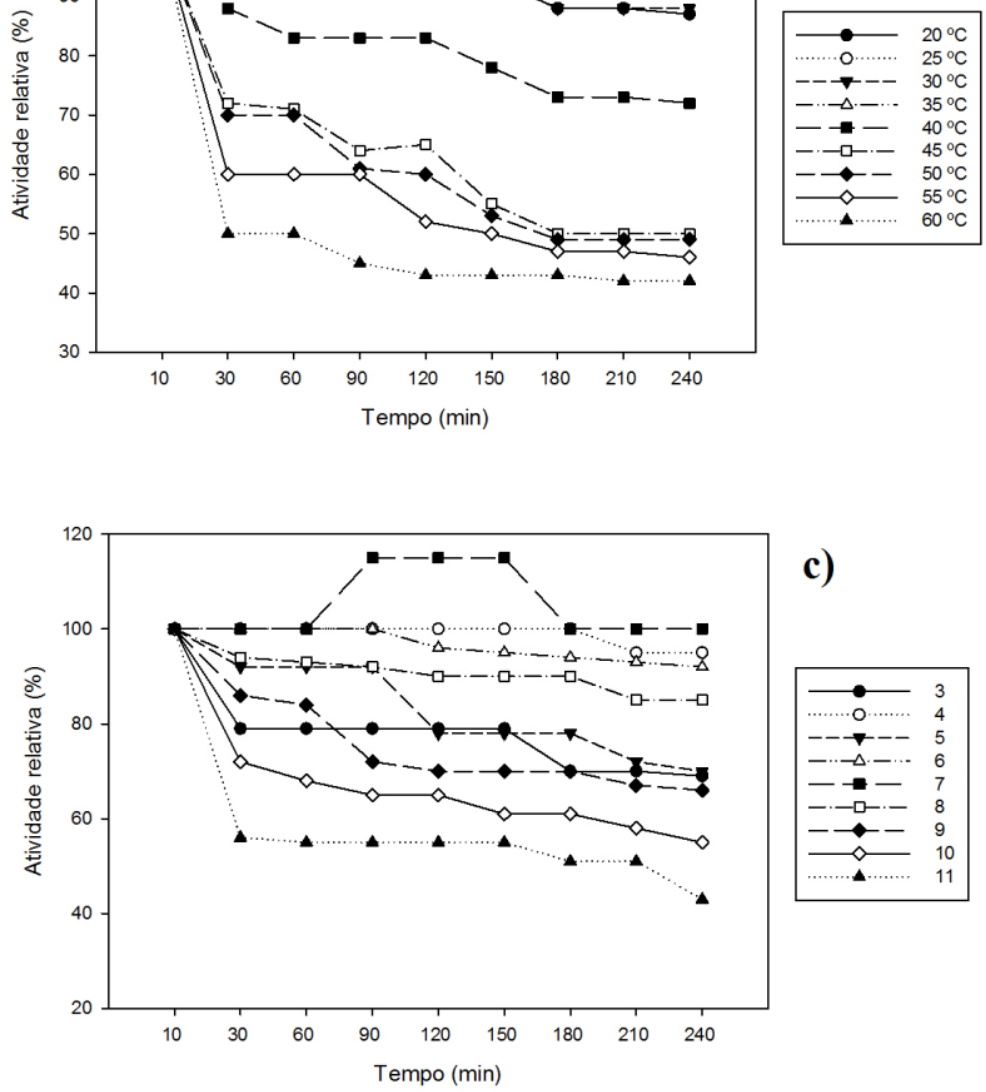

19 a 22 de outubro de 2014

Florianópolis/SC

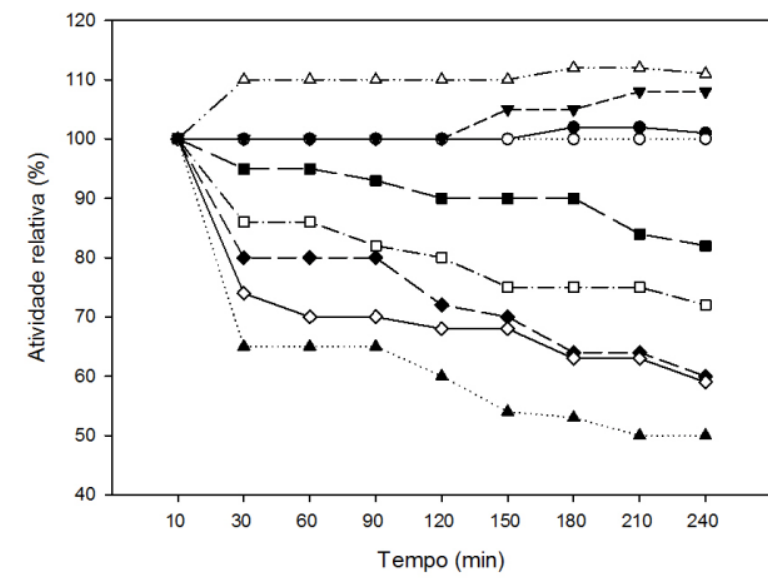

b)

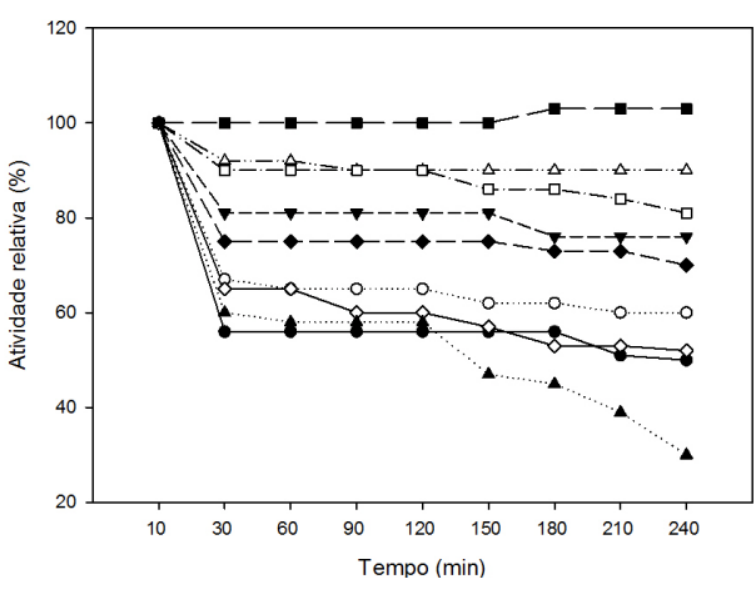

c)

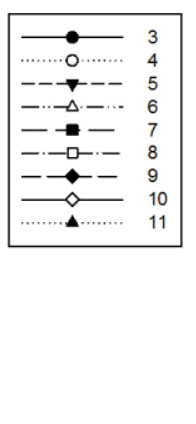

d)
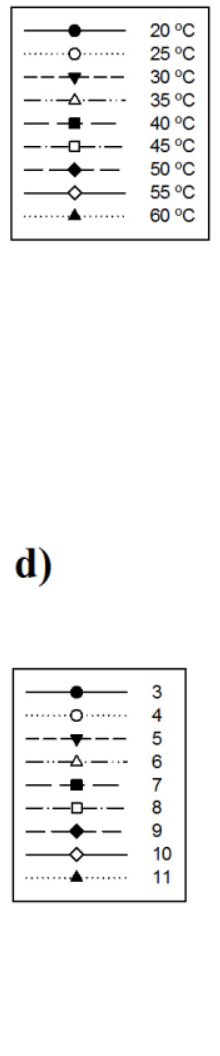

Figura 1. Estabilidade a temperatura (a) e $\mathrm{pH}$ (c) para a lipase com o tratamento com SAB, estabilidade a temperatura (b) e ao $\mathrm{pH}$ (d) para a lipase purificada com a ultrafiltração 


\section{CONCLUSÃO}

Com o uso dos sistemas de purificação é possível estabelecer que o uso do SAB é mais satisfatório, porém o sistema de ultrafiltração gera um menor custo no processo total, já que não é necessário o uso de reagentes e nenhum processo adicional para recuperação final da biomolécula. A enzima é estável a uma ampla faixa de temperatura e $\mathrm{pH}$, mesmo após os tratamentos de purificação, o que demostra aplicabilidade industrial futura.

\section{REFERÊNCIAS}

AMARAL, P. F. F. Produção de lipase de Yarrowia lipolytica em Biorreator Multifásico. 2007. 220 p. 29,7 cm. Tese (Doutorado) - Universidade Federal do Rio de Janeiro - UFRJ, Programa de Pós-Graduação em Tecnologia de Processos Químicos e Bioquímicos - EQ, 2007.

BRADFORD, M. M., A rapid and sensitive method for the quantitation of microgram quantities of protein utilizing the principle of protein-dye binding. Analytical Biochemistry. v.72, n.1-2, 248-254. 1976,

BREUER, M., DITRICH, K., HABICHER, T., HAUER, B., KESSELER, M., STURMER, R., ZELINSKI, T., BROCKMAN, H. L., BORGSTROM, B., Industrial methods for the production of optically active intermediates. Angewandte Chemie International., n.43, v.7, p.788-824. 2004

COIMBRA, J.S. R.; TEIXEIRA, J. Engineering Aspects of Milk and Dairy Products. BocaRaton, CRC Press, 2009.

JAEGER, K. E., EGGERT, T., Lipases for biotechnology. Current Opinion in Biotechnology, v.13, n.4, p.390-397, 2002.

KORDEL, M., HOFMANN, B., SCHOMBURG, D., SCHMID, R. Extracellular lipase of Burkholderia sp Strain ATCC 21808: purification, characterization, crystallization and preliminary X-ray diffraction data. Journal of Bacteriology, v. 177, p. 4836-4841, 1991.

MACEDO, G.A., PARK, Y.K., PASTORE, G.M. Partial purification and characterization of an extracellular lipase from a newly isolated strain of Geotrichum sp. Journal of the Brazilian Society for Microbiology, v. 28, p. 90-95, 1997.

PADILHA, G. S.; CURVELO-SANTANA, J. C.; ALEGRE, M. R.; TAMBOURGI, E. B. Expanded bed adsorption of an alkaline lipase from Pseudomona cepacia. Journal of Chromatography B, v. 877, p. 521- 526, 2009.

PADILHA, G.S., CASTIGIONI, G.L., MONTE ALEGRE, R., TAMBOURGI, E.B. Avaliação de diferentes íons na atividade da lipase de Pseudomonas cepacia. Exacta, v.7, n. 2, p. 181-186, 2010. 
SAXENA, R. K.; SHEORAN, A.; GIRI, B.; DAVIDSON, W. S. Purification strategies for microbial lipases. Journal of Microbiological Methods, v. 52, p. 1-18, 2003.

ZAREVUCKA, M., ZALSKA, Z., REJZEK, M., STREINZ, L., WIMMER, Z., MACKOVA, M., DEMNEROVA, K., Lipase-mediated hydrolysis and esterification. Enzyme Microbiology Technology, v.17, n.10, p.866-869, 1995. 